Supporting Information

\title{
Aerobic Oxidation of Benzylic Carbons Using a Guanidine Base
}

\author{
Seulchan Lee ${ }^{a}$, Si Ae Kim ${ }^{a}$, Hye-Young Jang a,* \\ ${ }^{a}$ Department of Energy Systems Research, Ajou University, Suwon 16499, Korea
}

I. $\quad{ }^{1} \mathrm{H}$ and ${ }^{13} \mathrm{C}$ NMR spectra of benzamides, and ketones .................................................. 2 
Figure S1

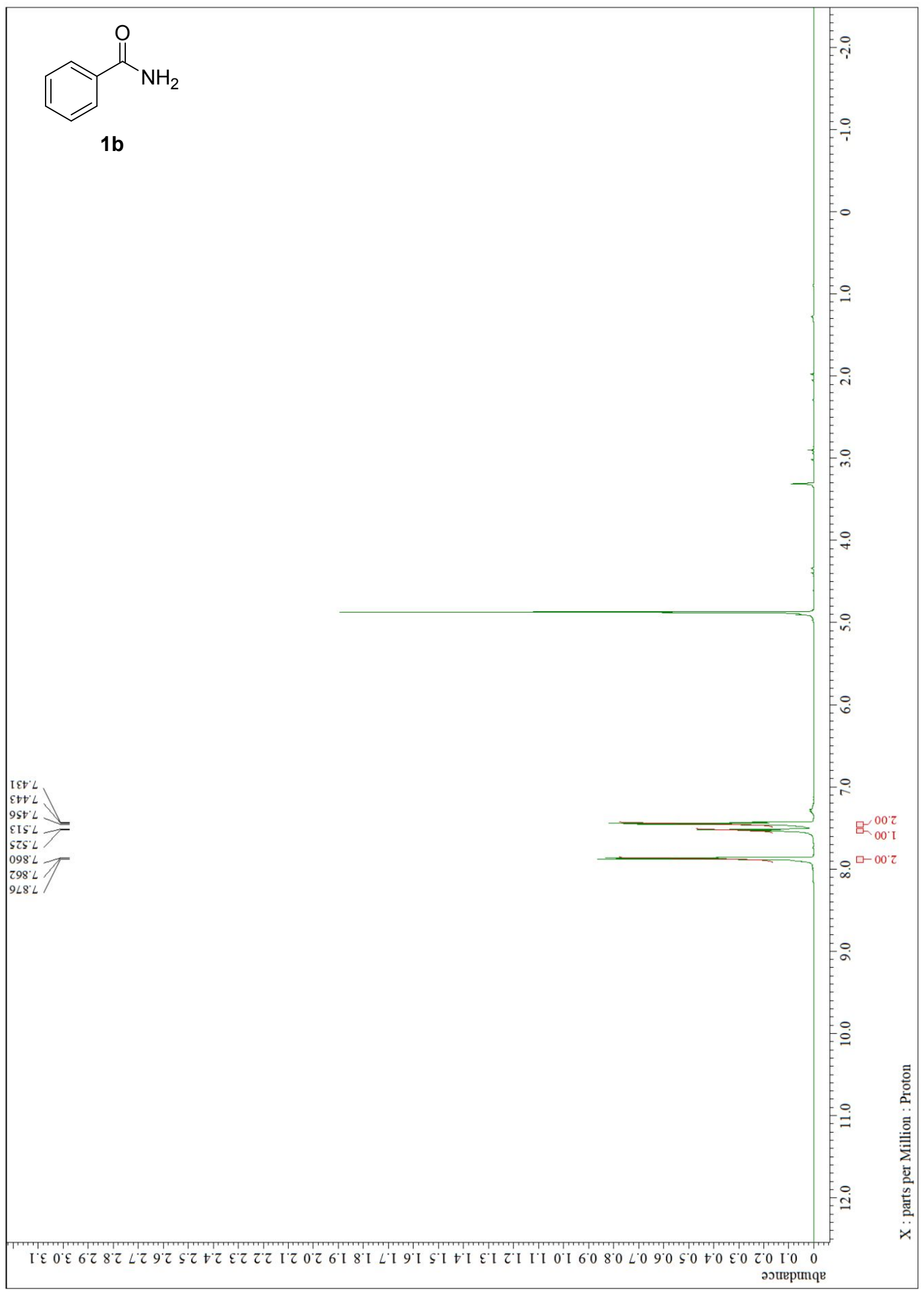


Figure S2

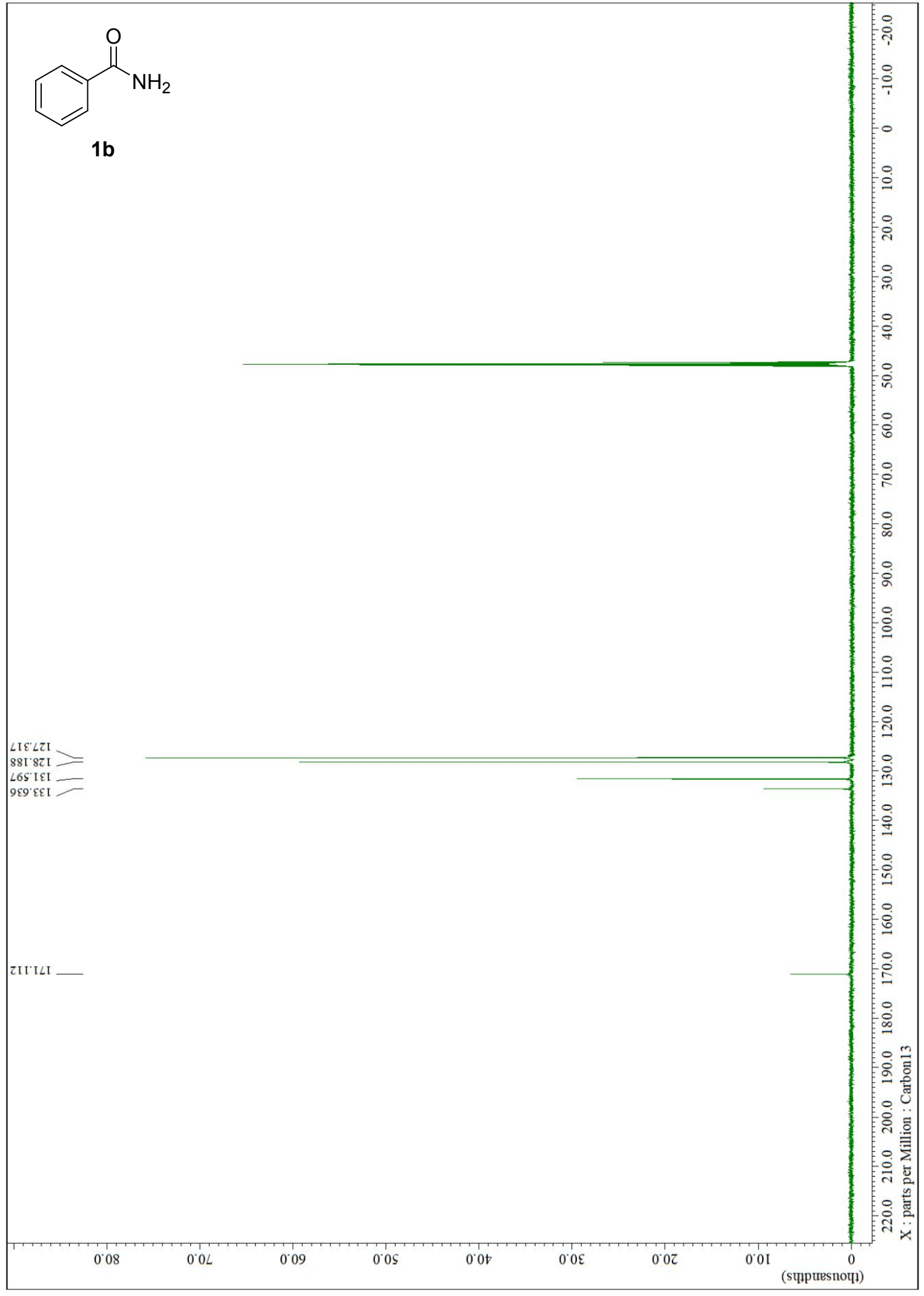


Figure 35

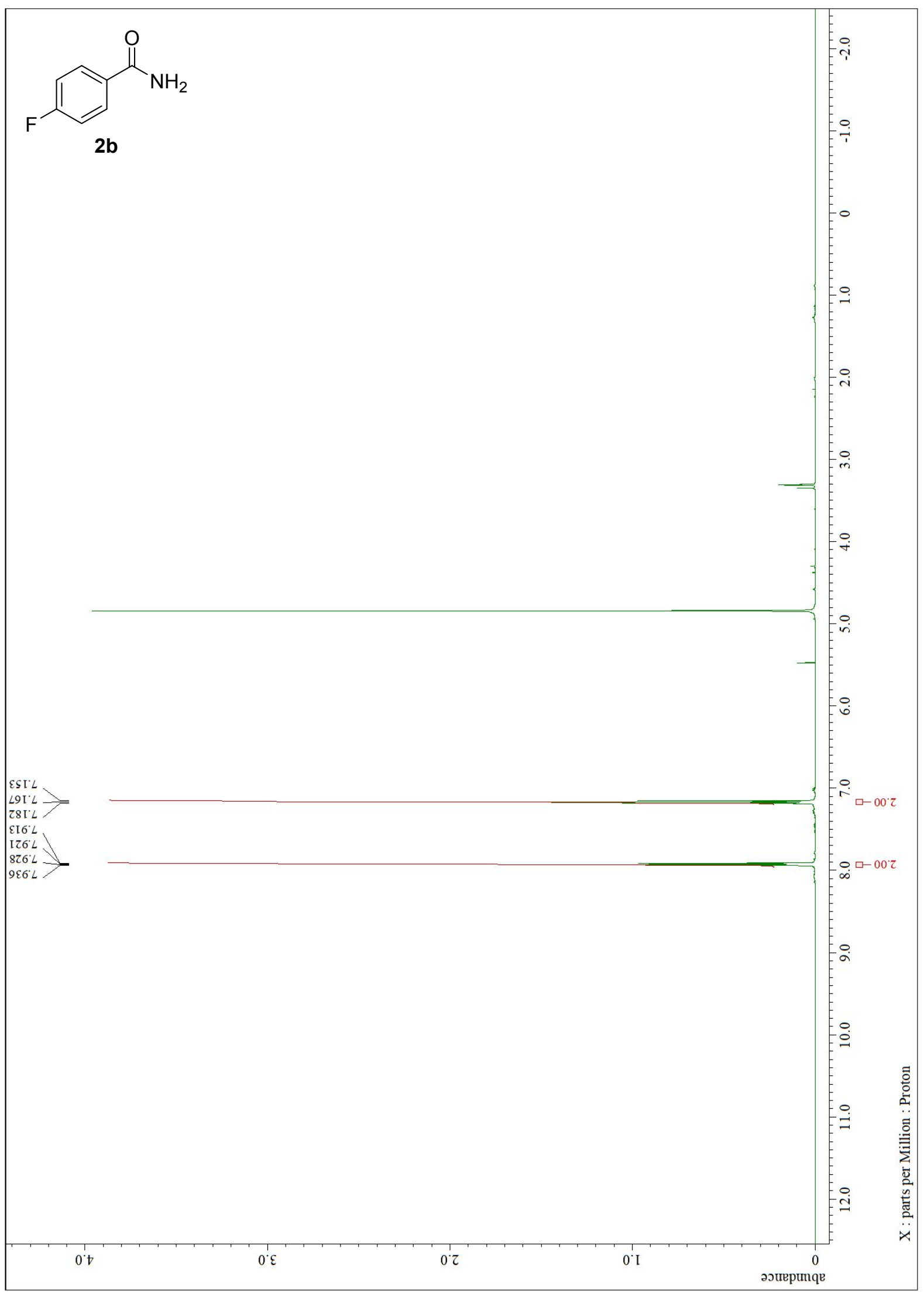


Figure $4 \mathrm{~S}$

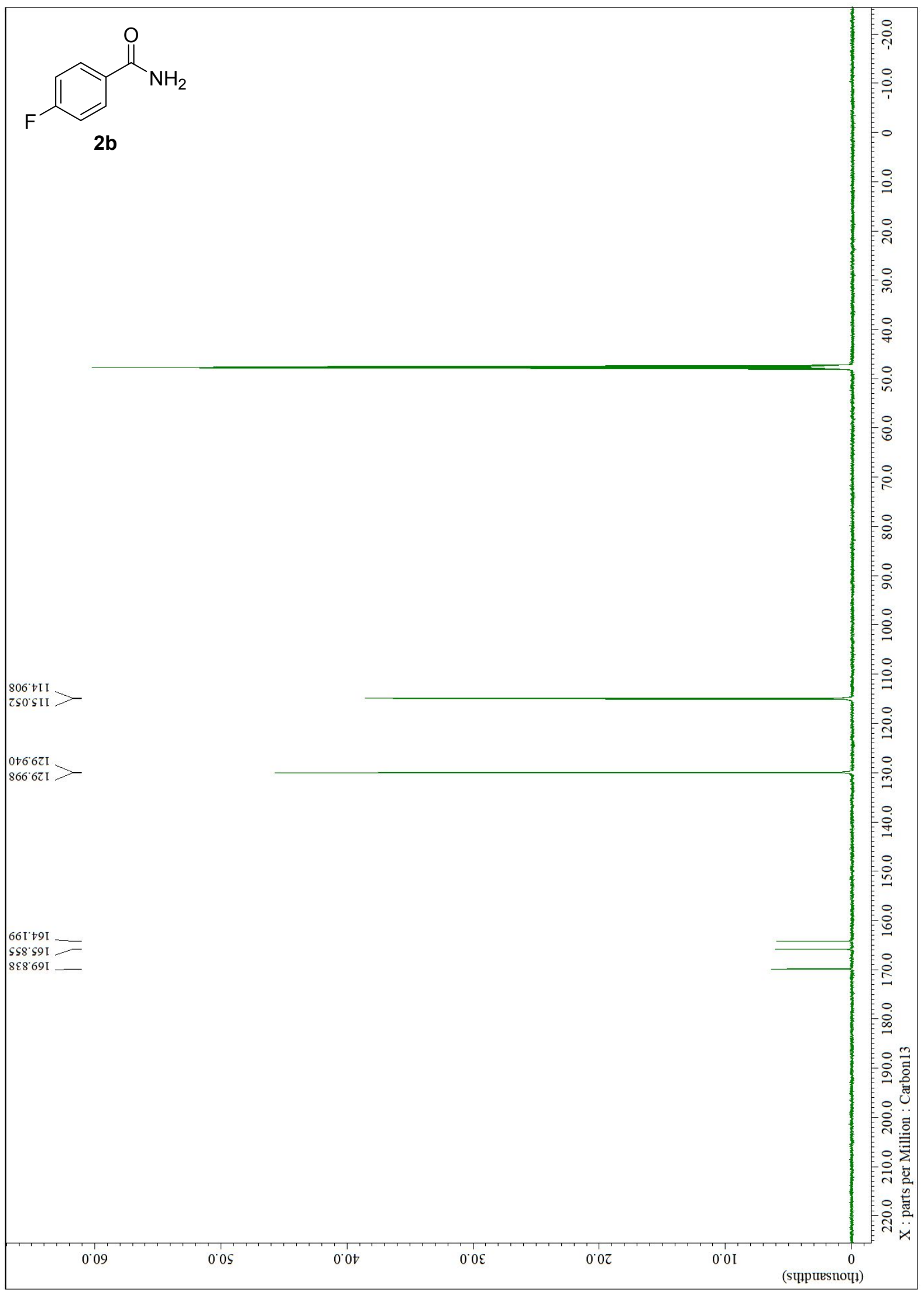


Figure 5S

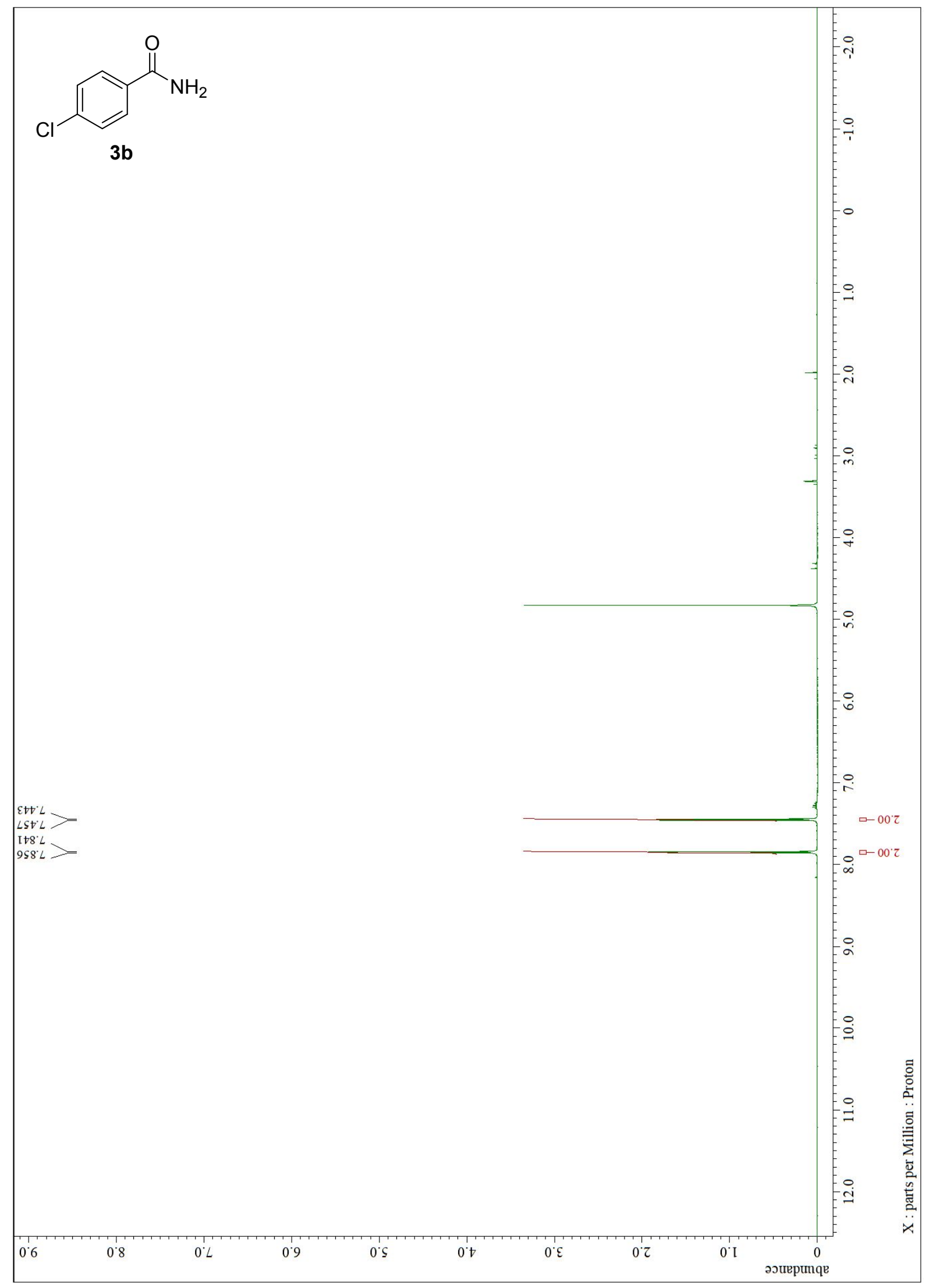


Figure 6S

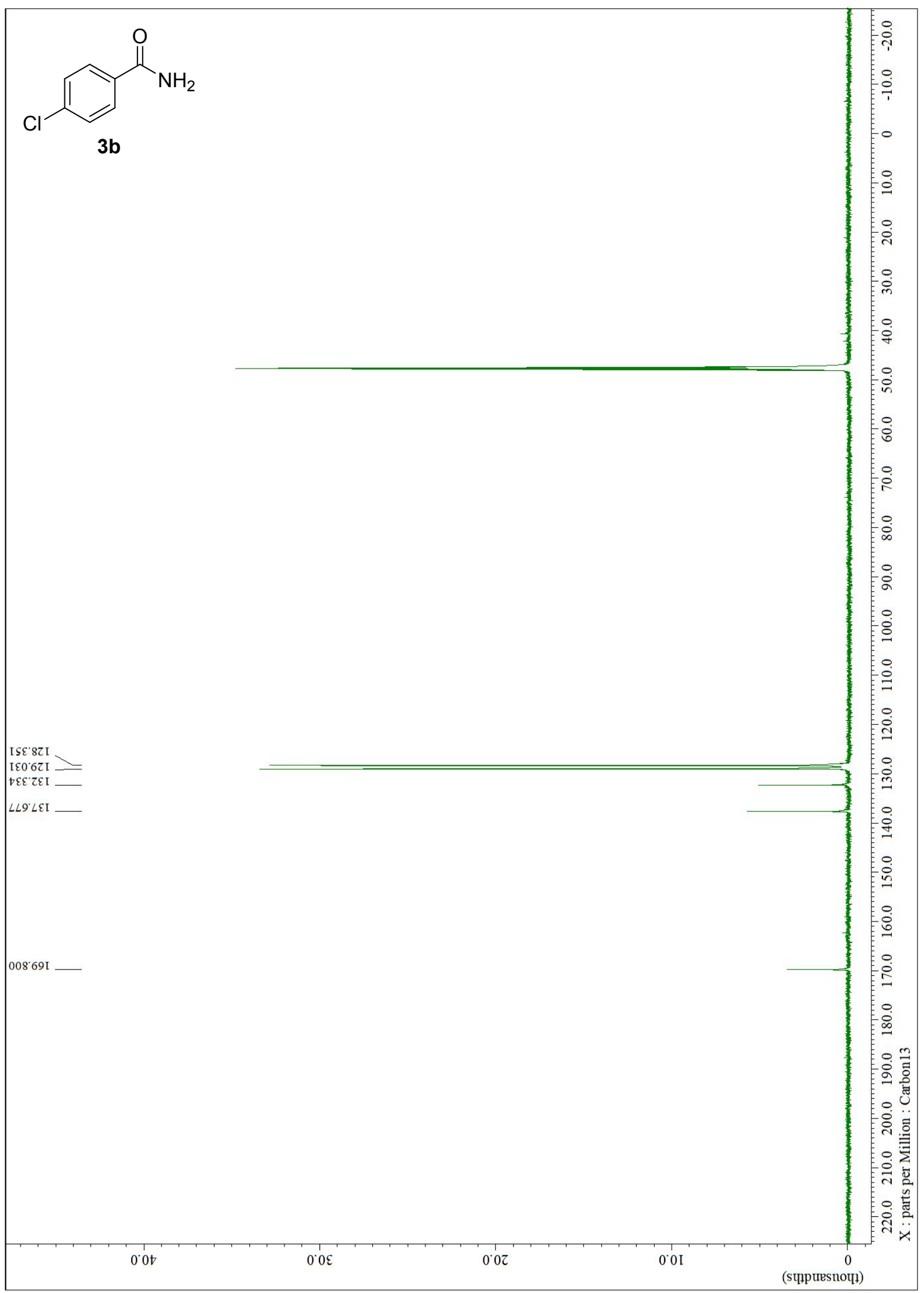


Figure 75

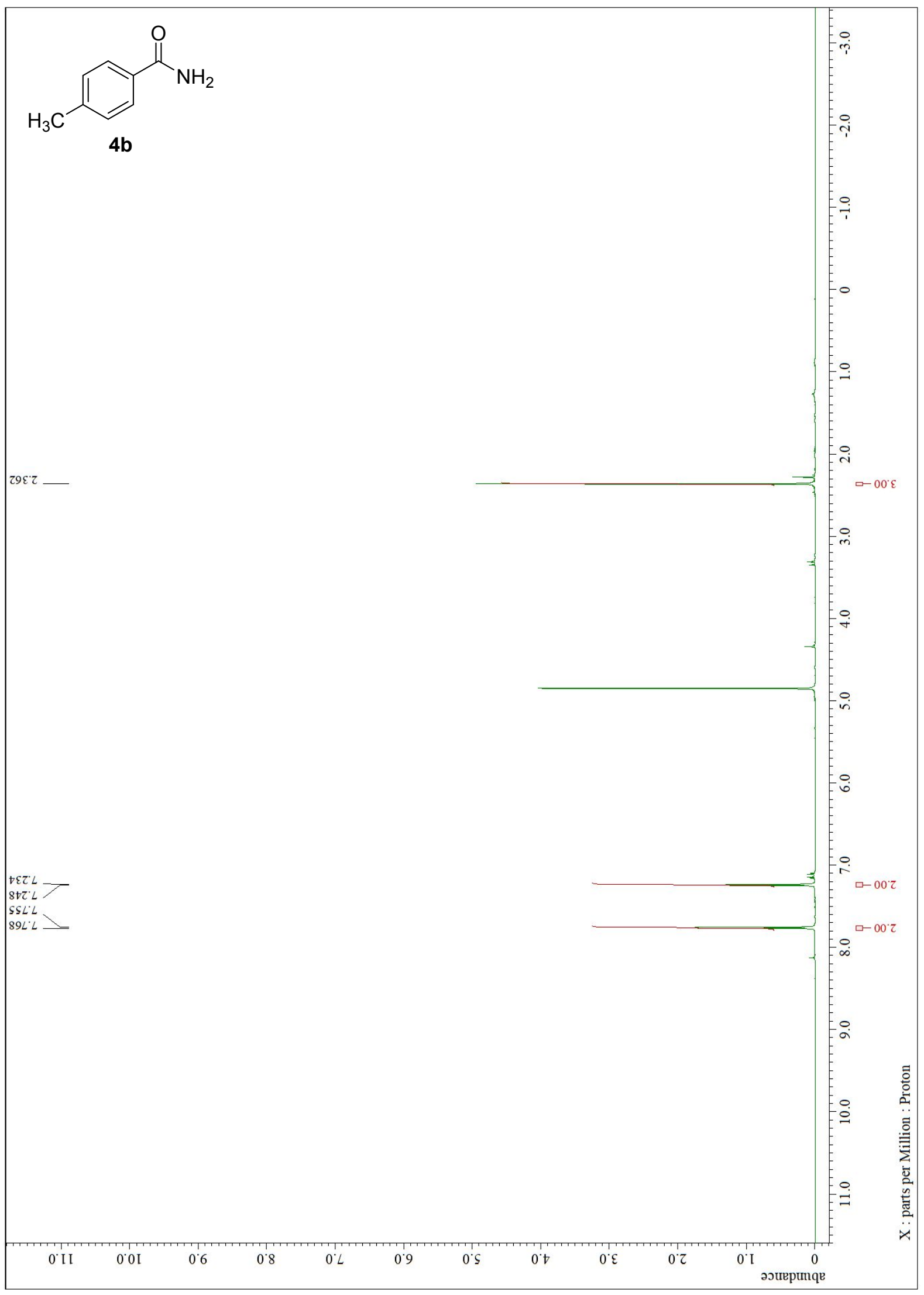


Figure 85

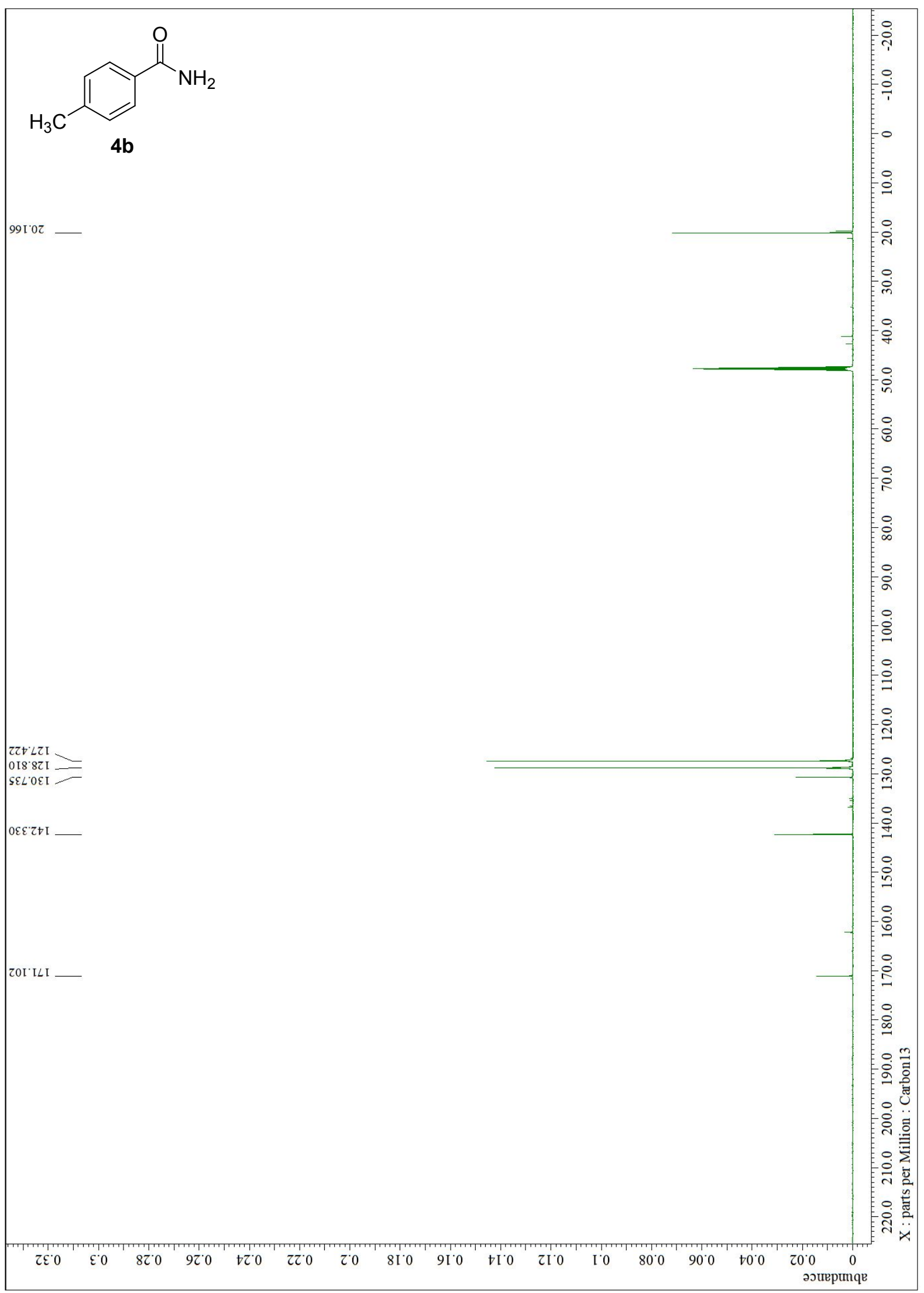


Figure 9S

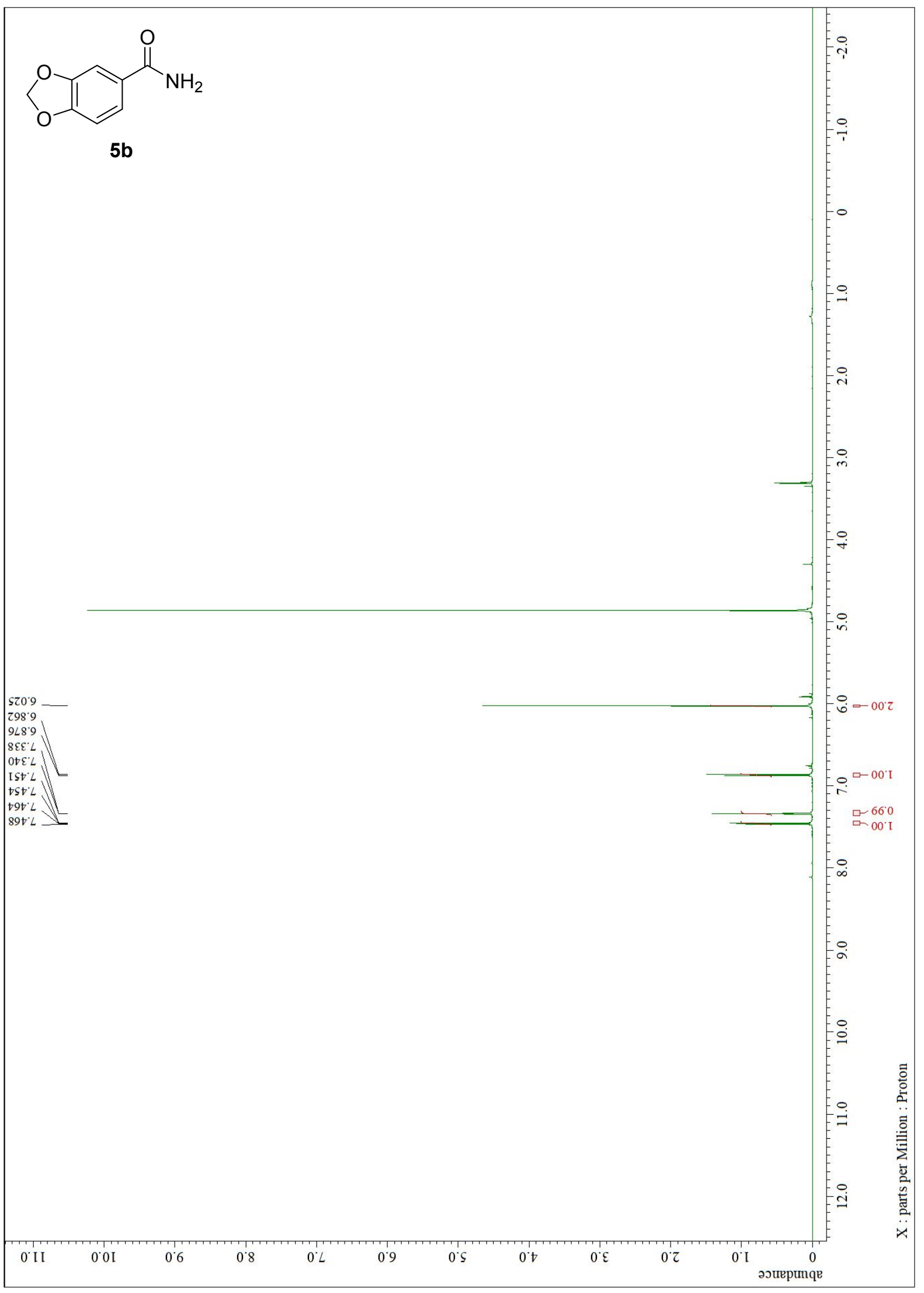


Figure 10S

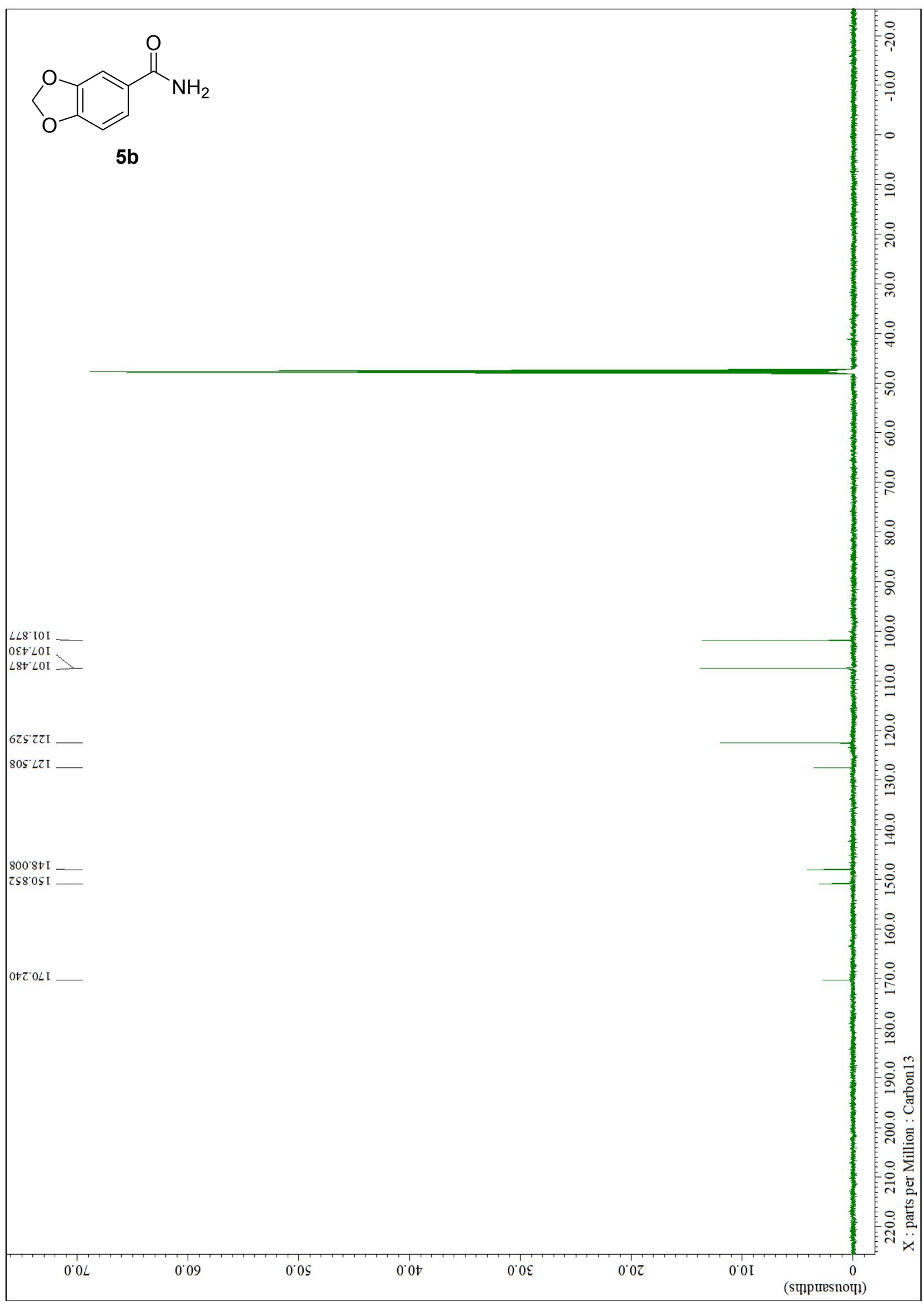


Figure 11S

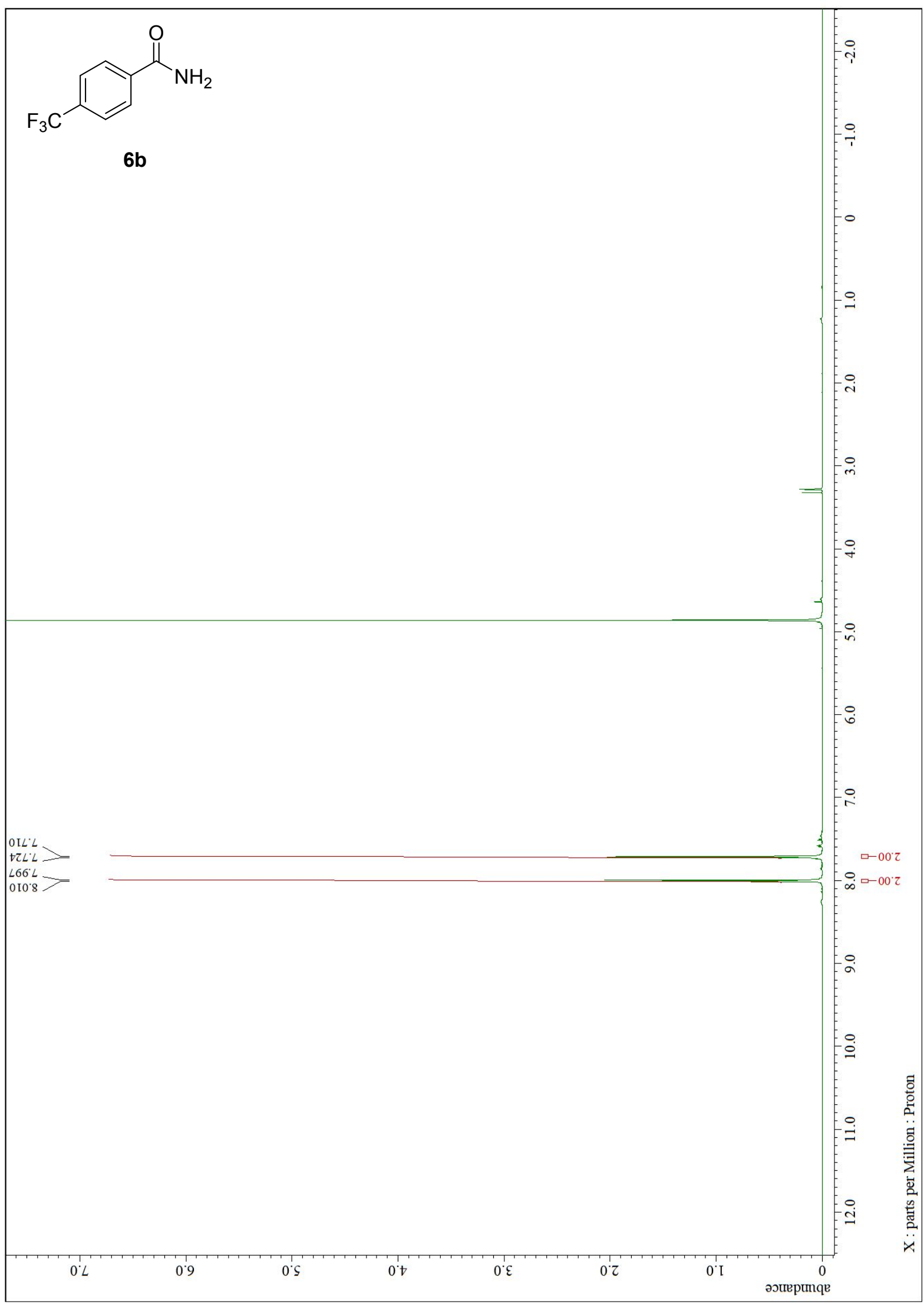


Figure $12 S$

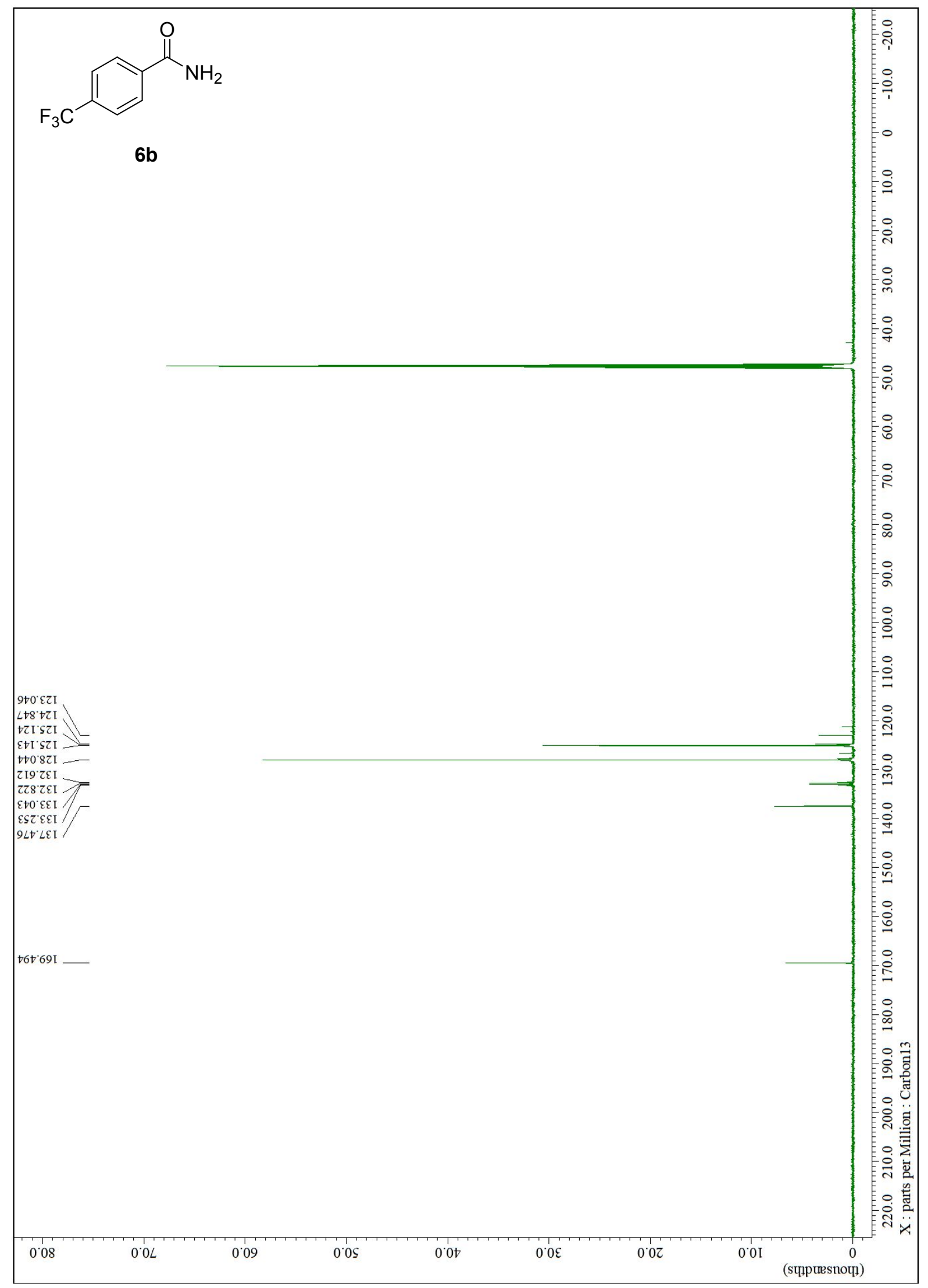


Figure 13S

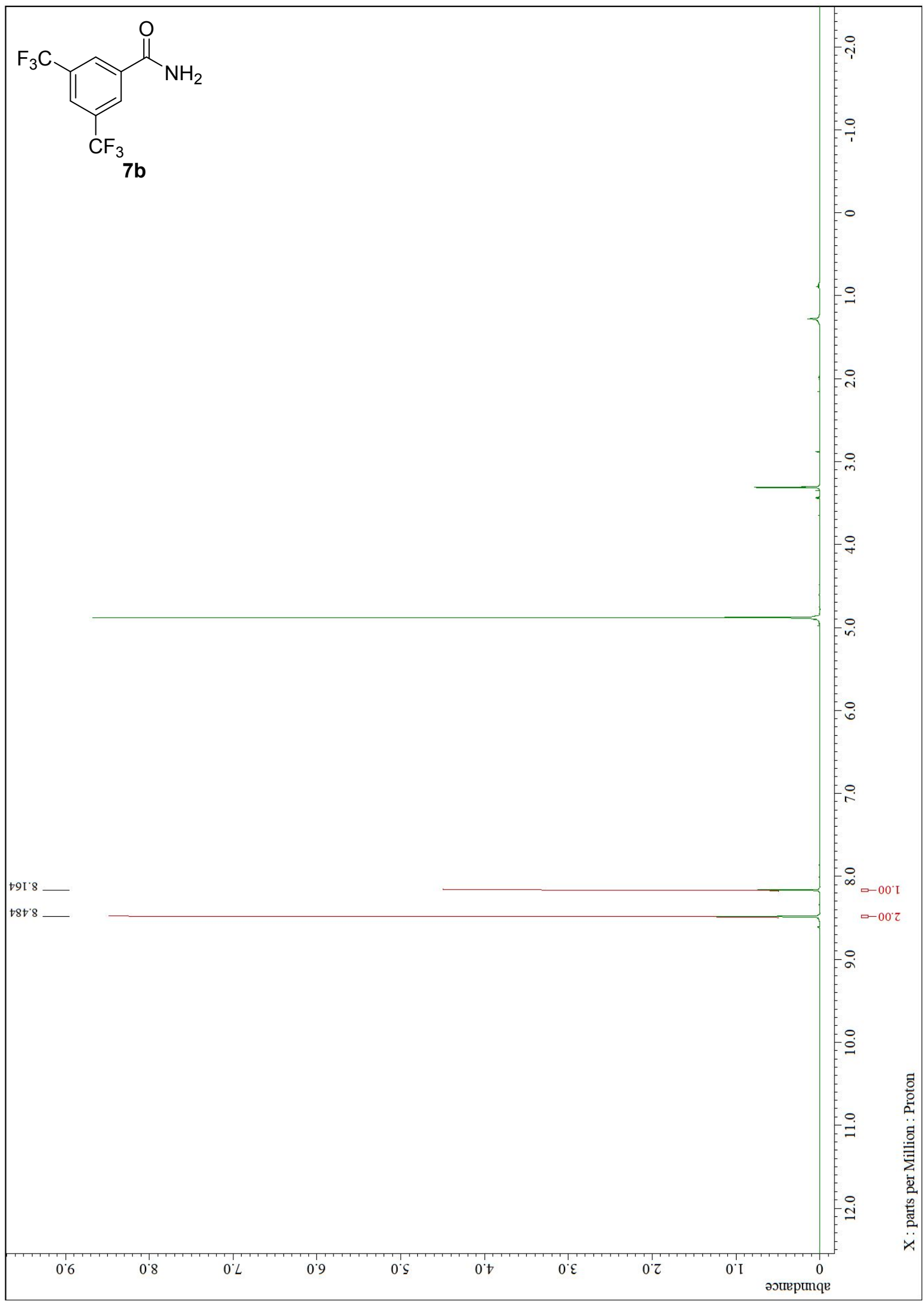


Figure 14S

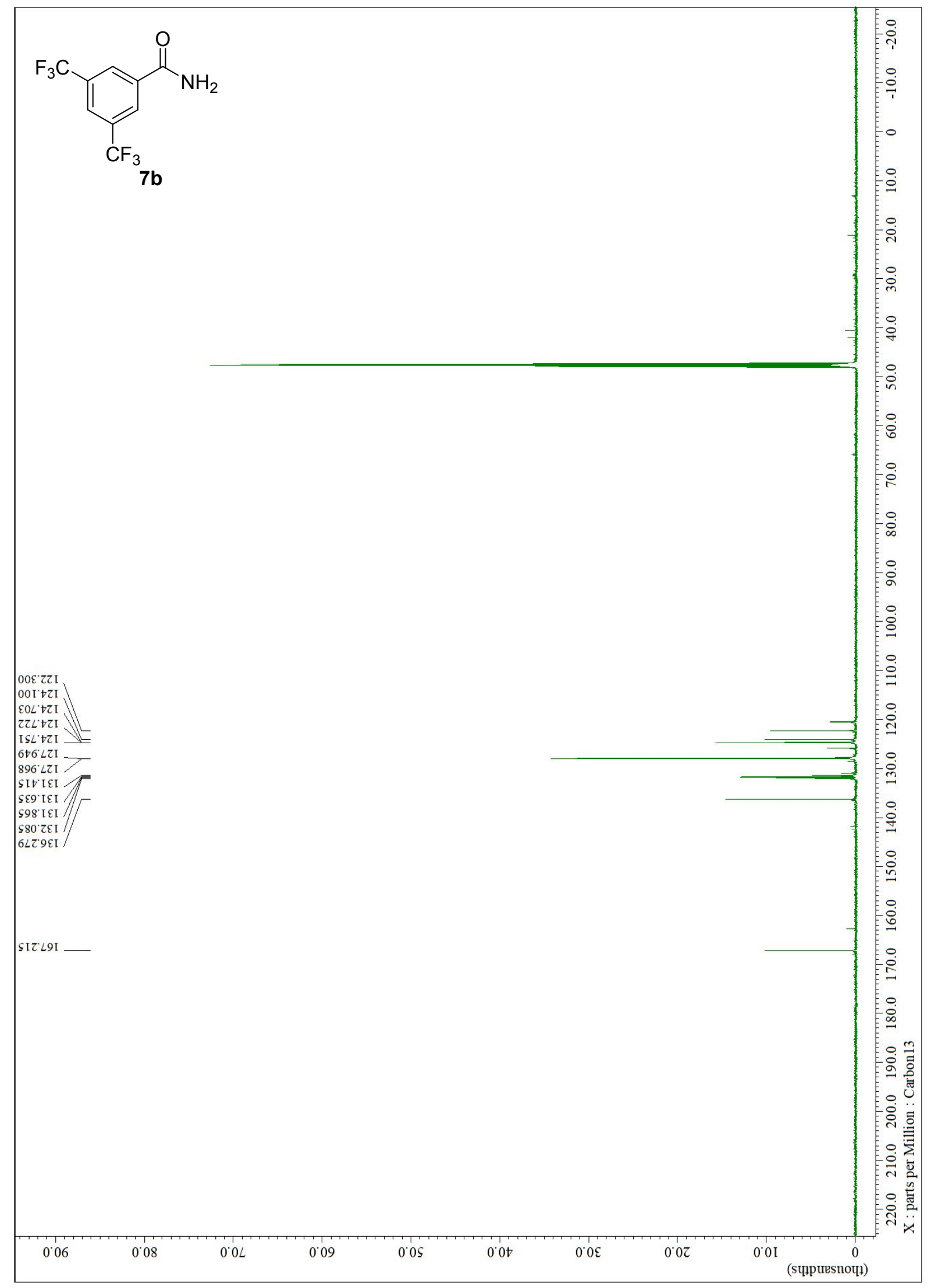


Figure 15S

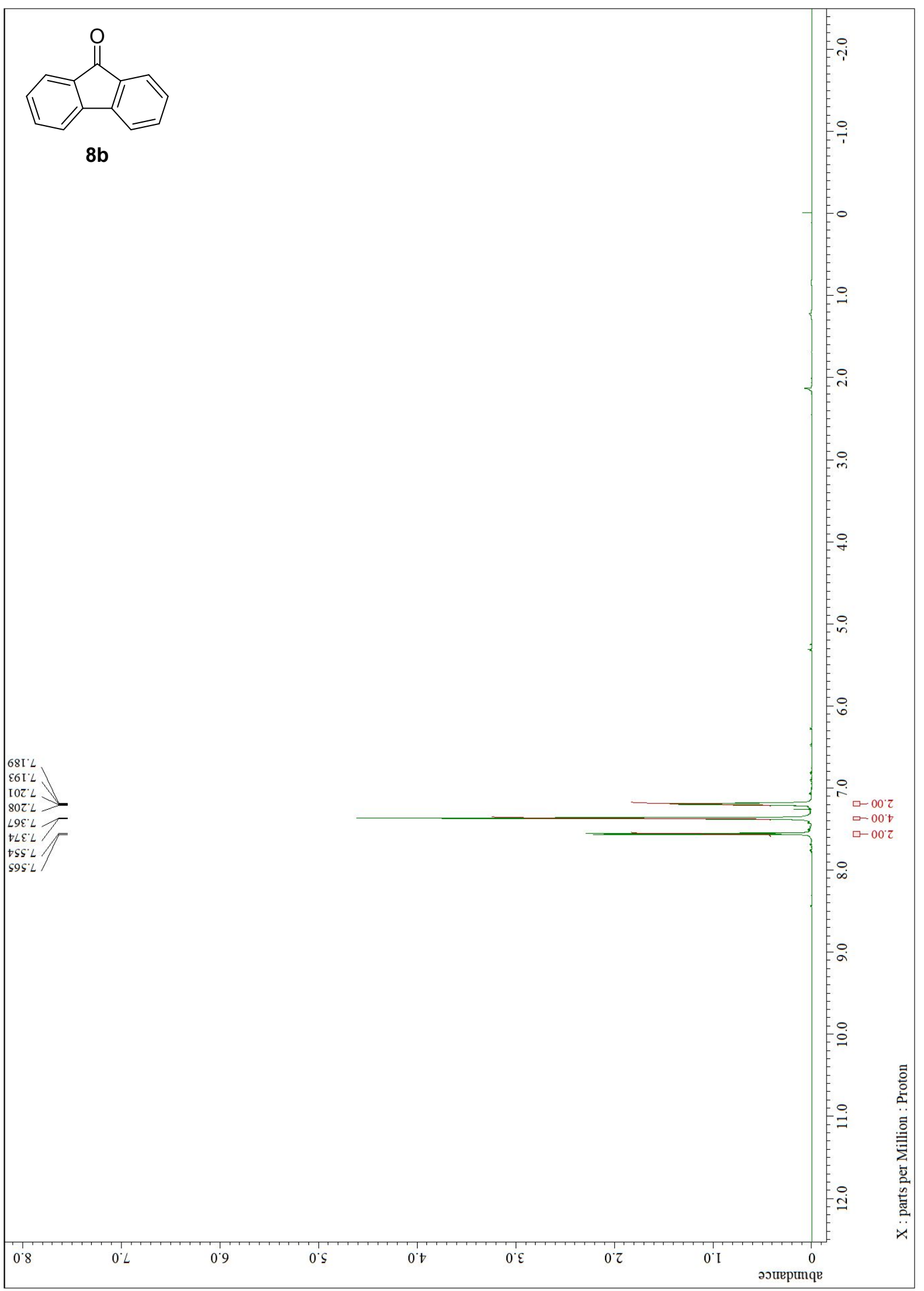


Figure 16S

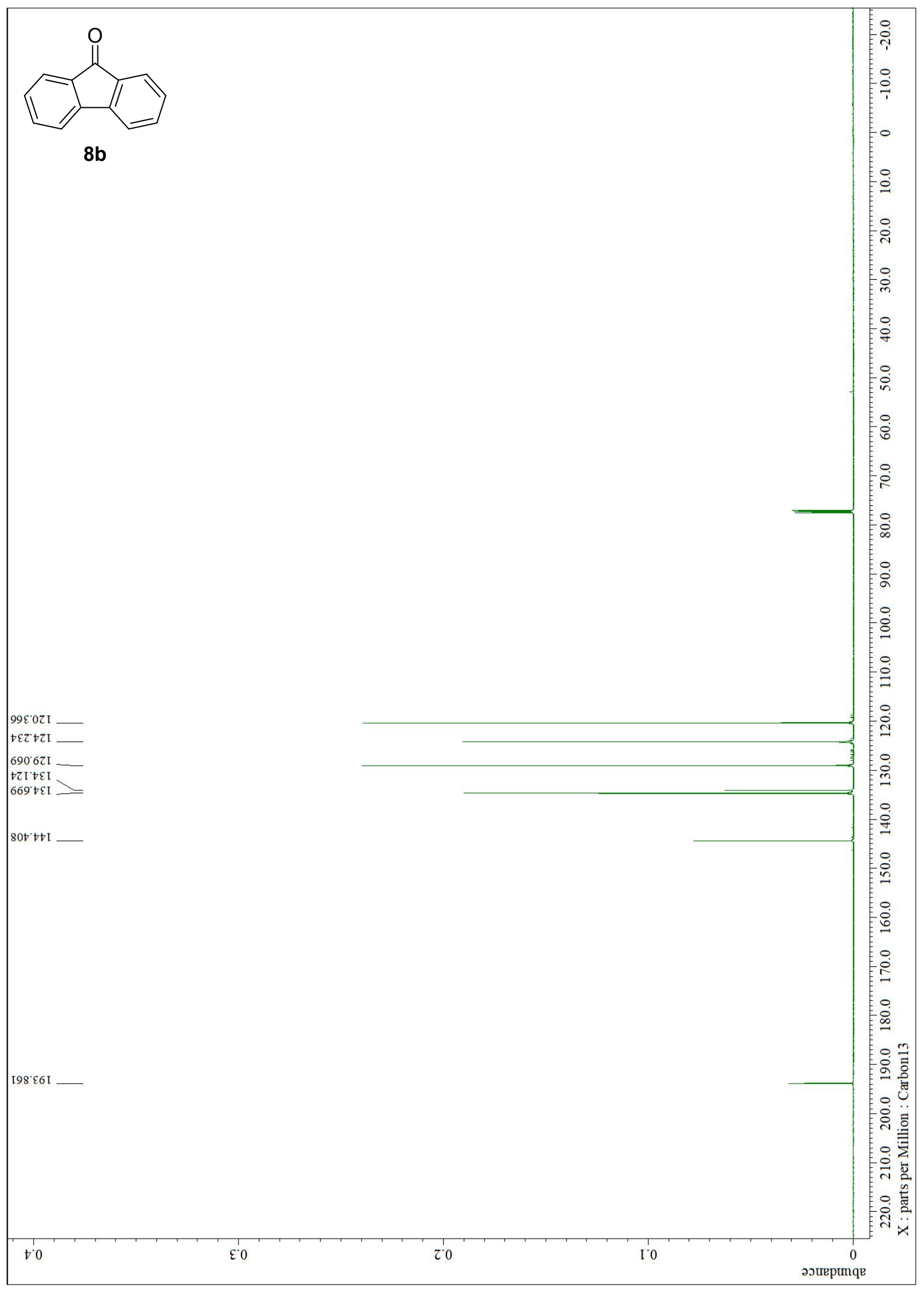


Figure 17S

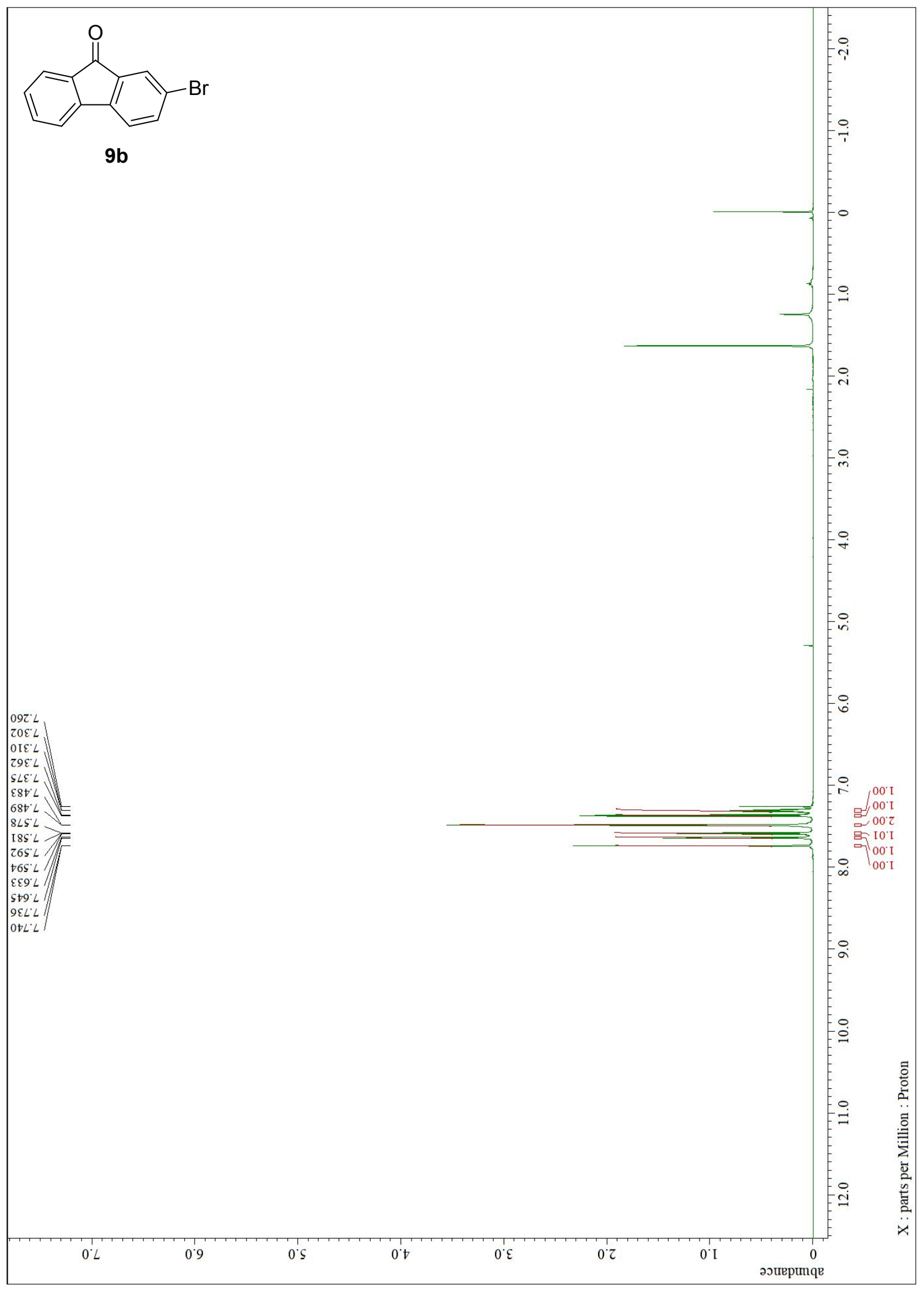


Figure 18S

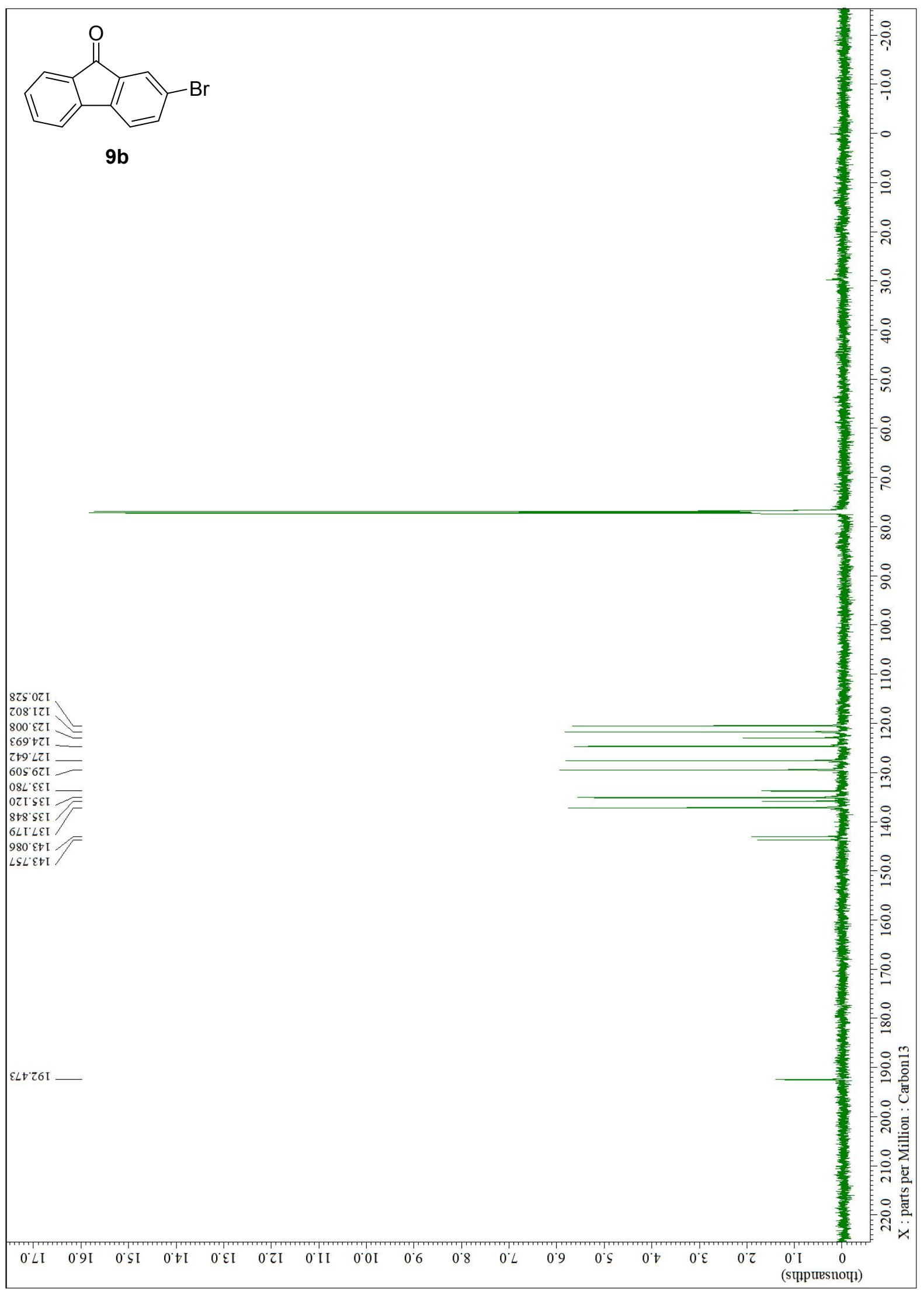


Figure 19S

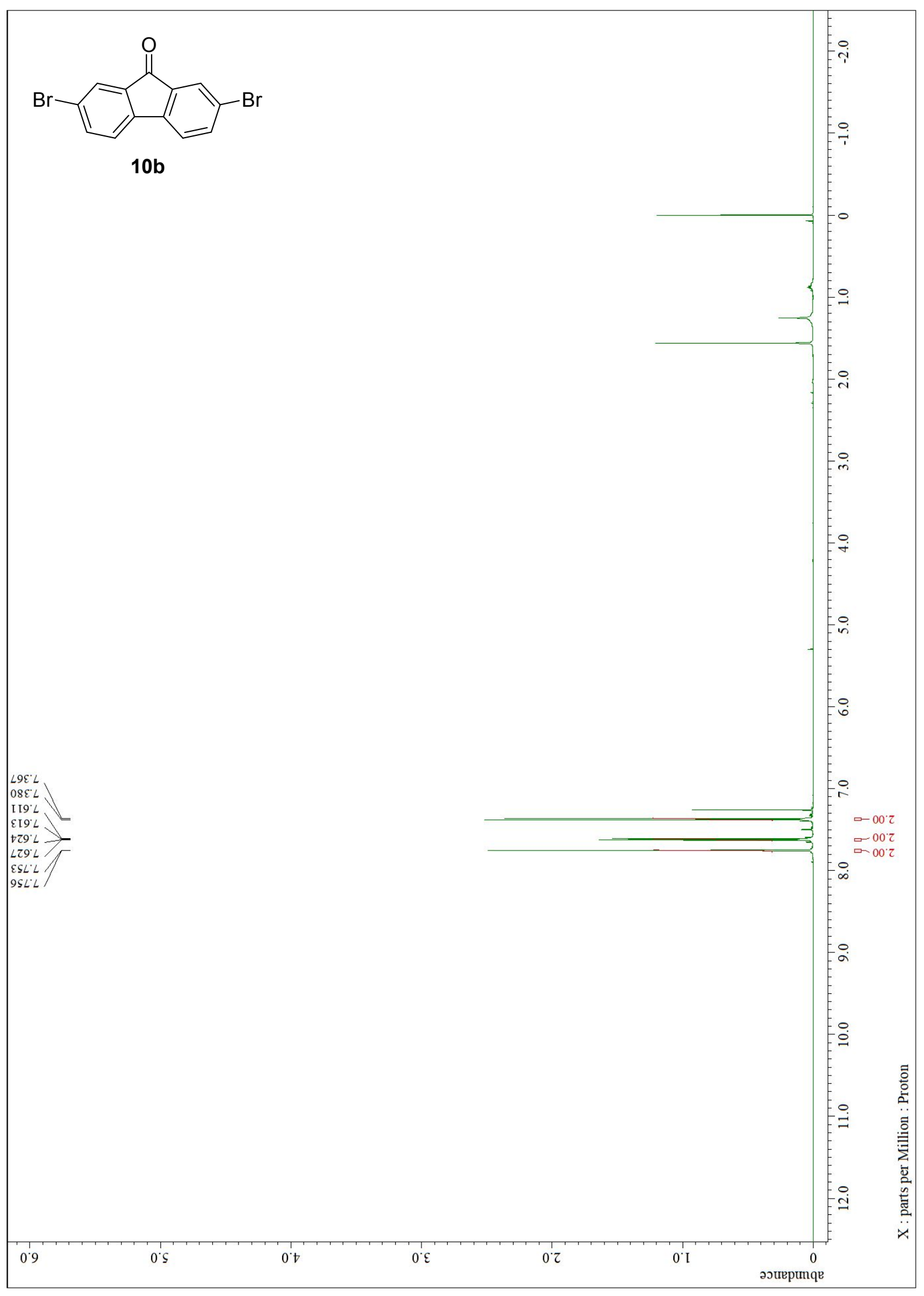


Figure 20S

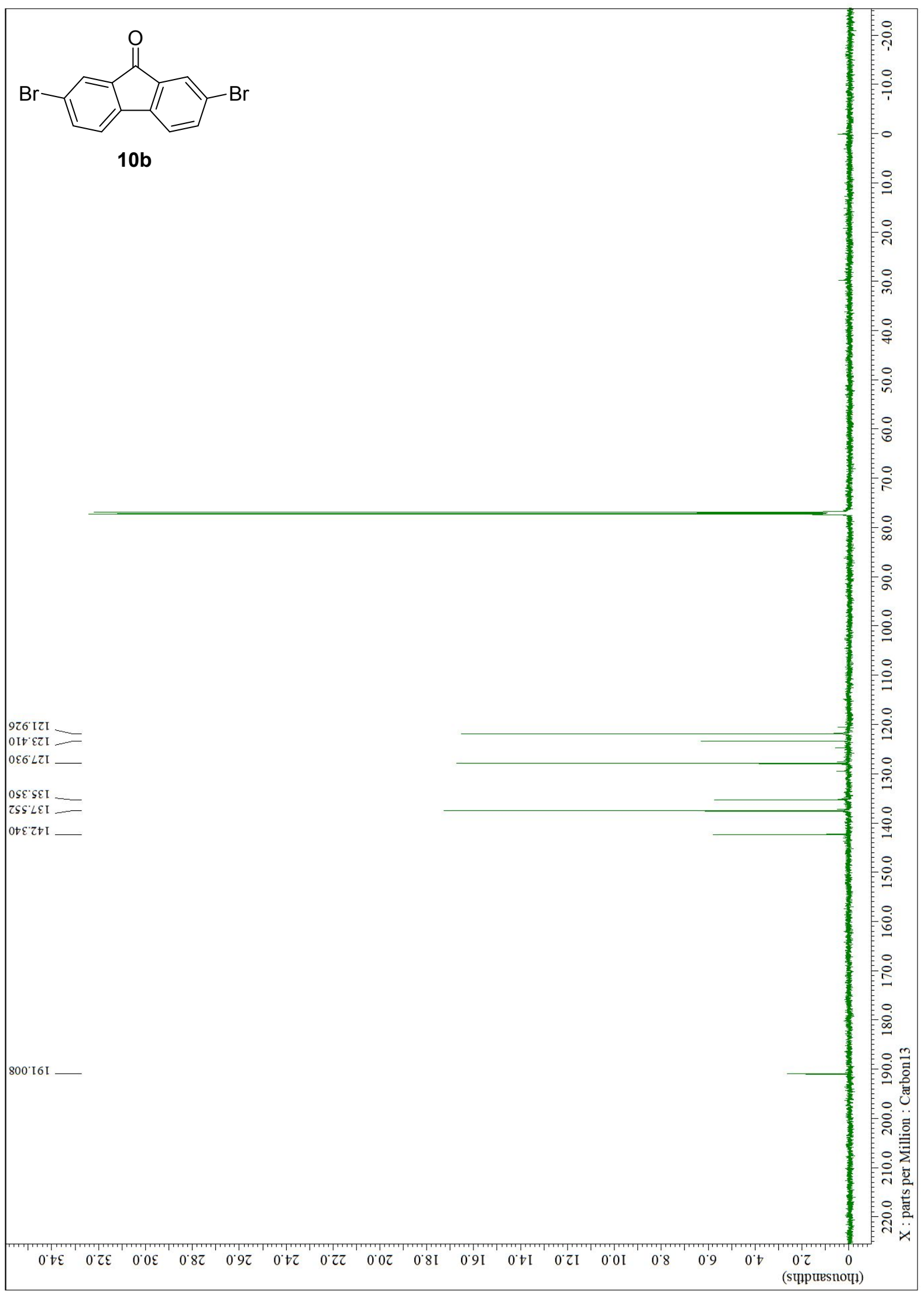


Figure 21S

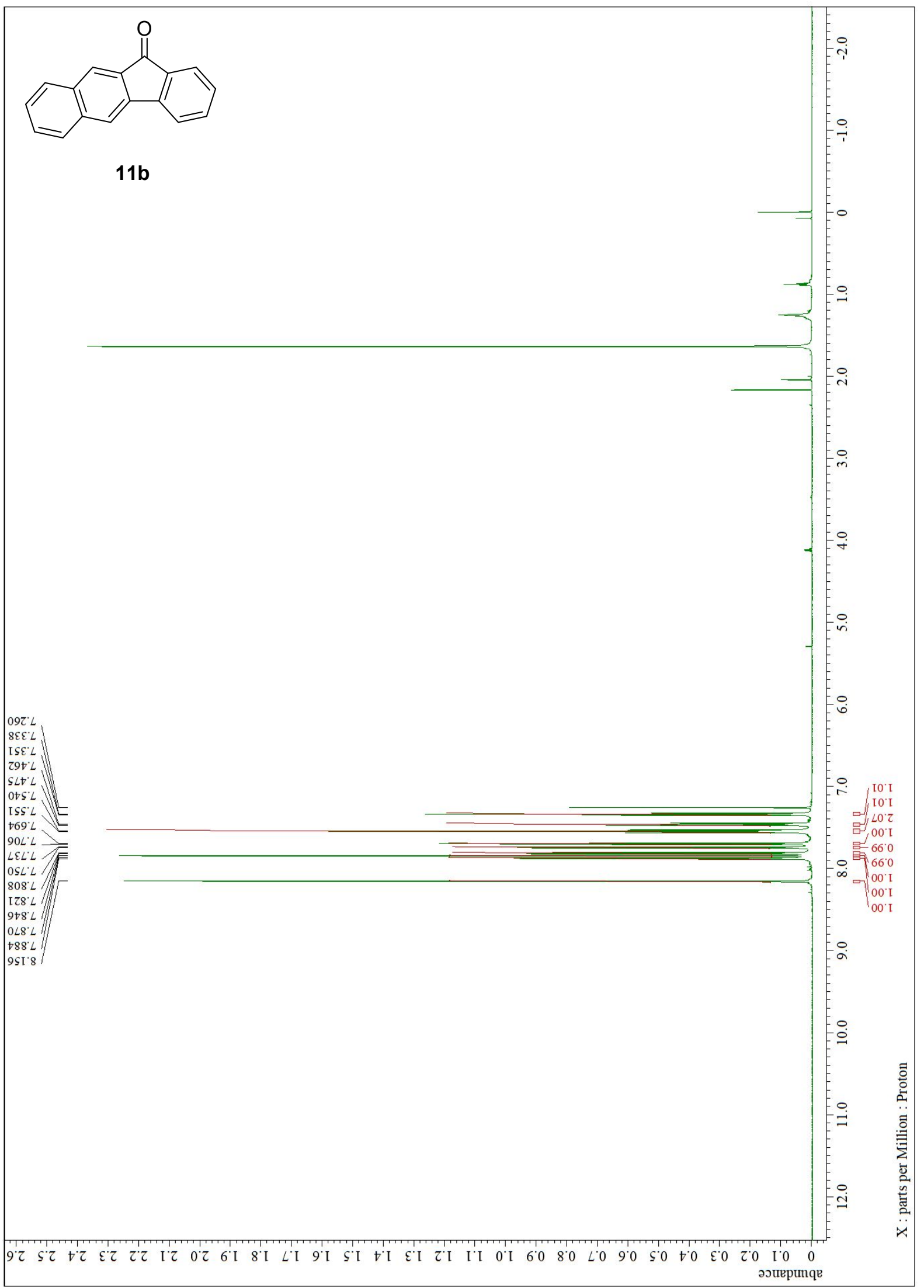


Figure 22S

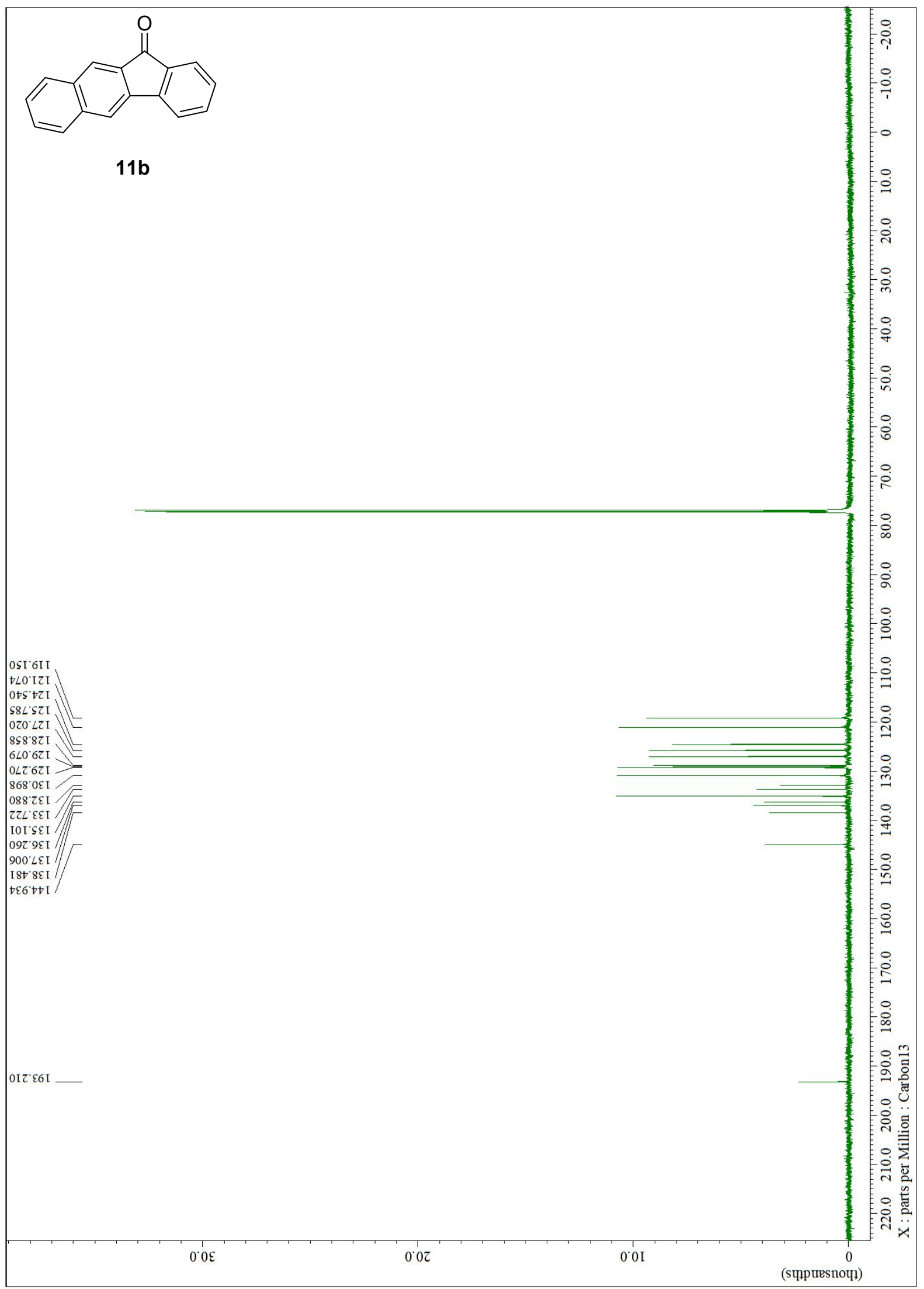


Figure 23S

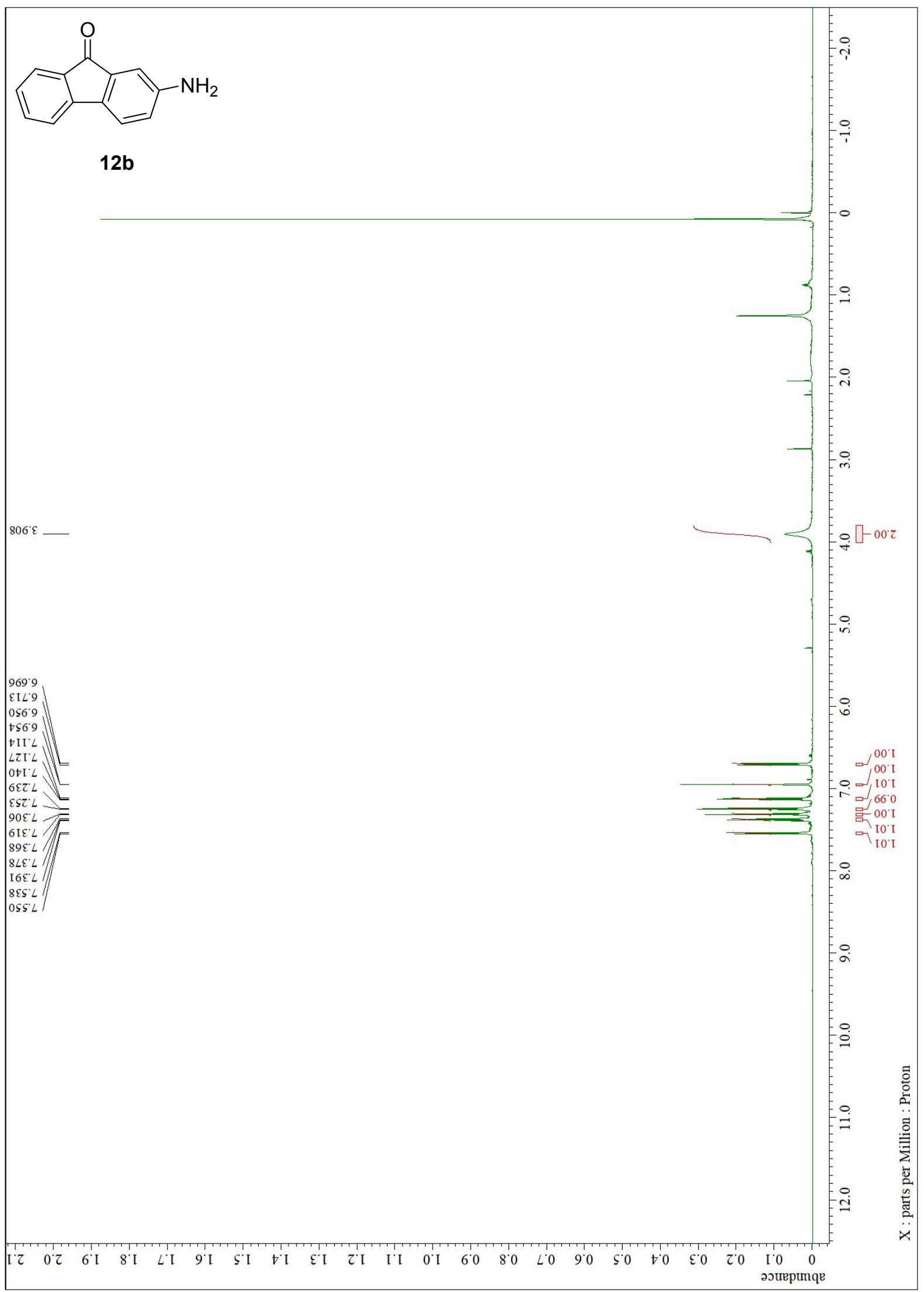


Figure 24S

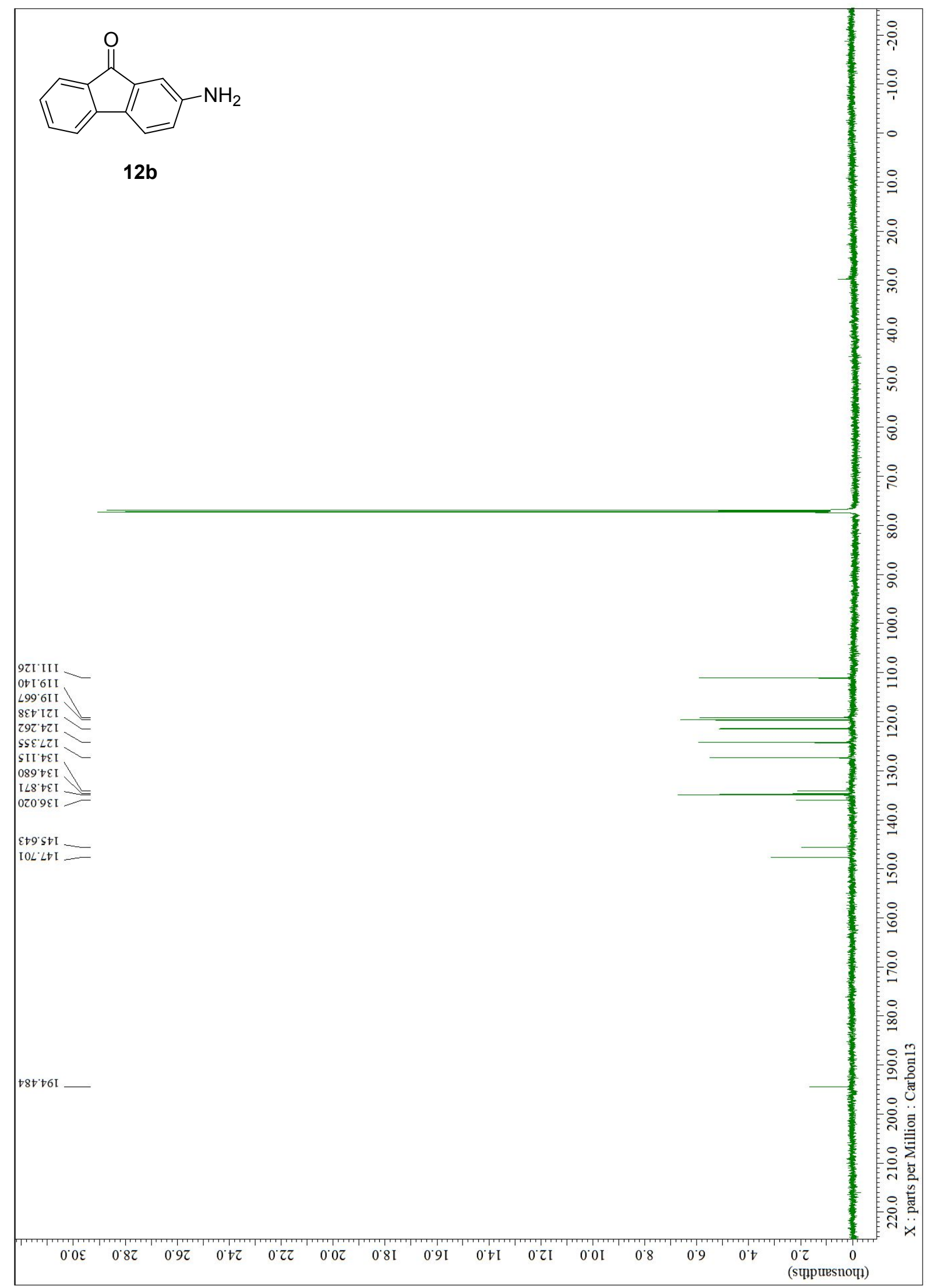


Figure 25S

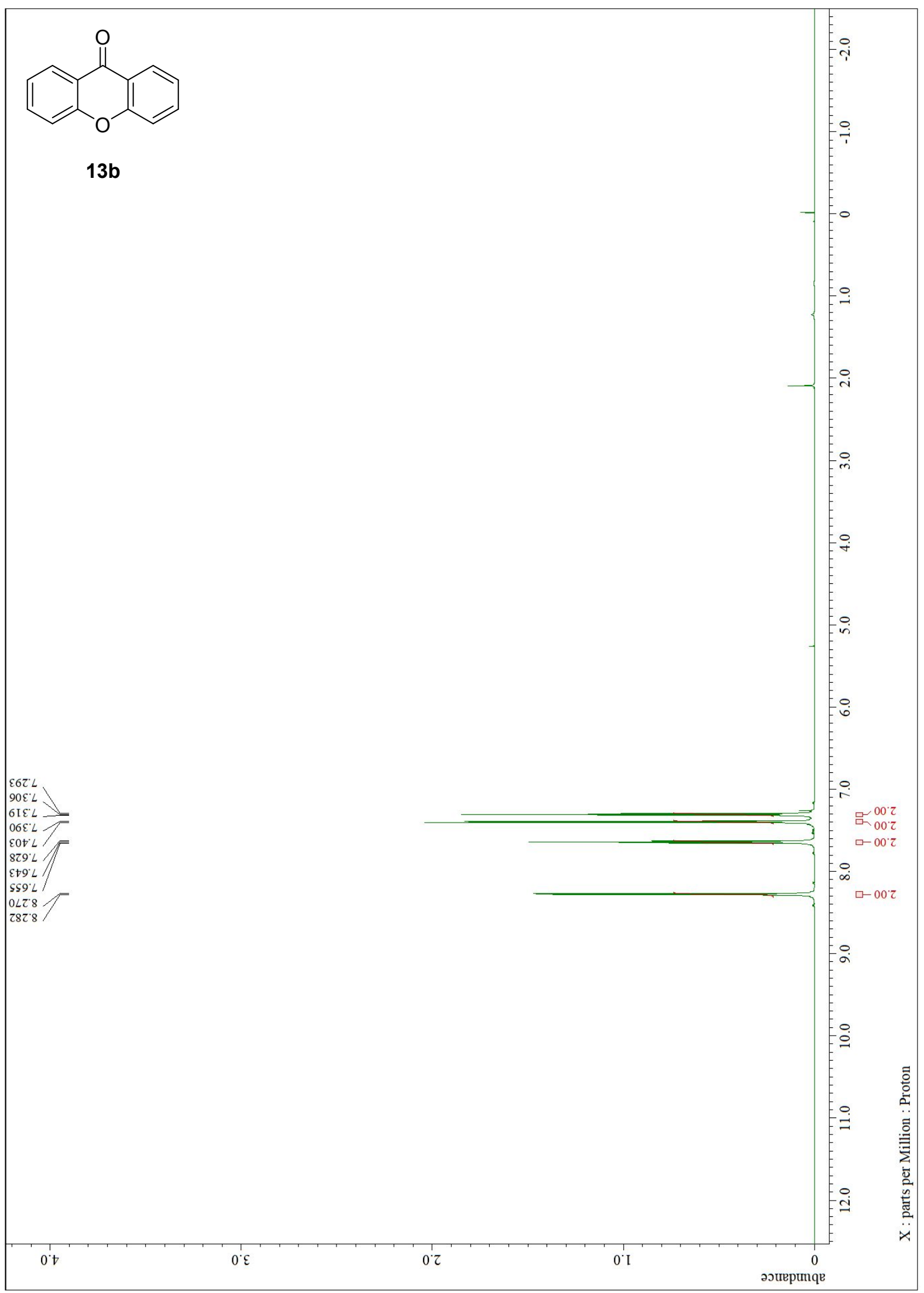


Figure 26S

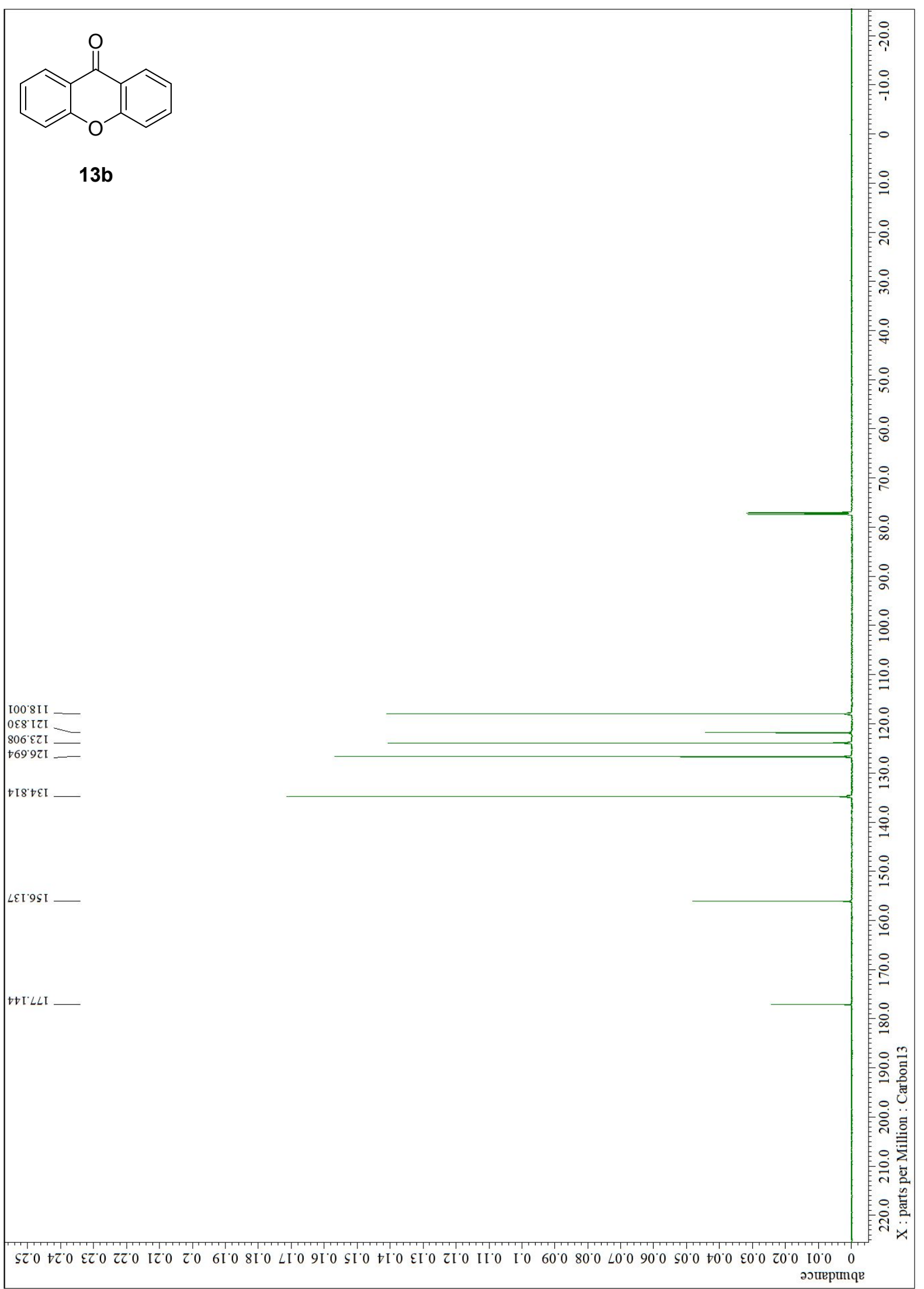


Figure 27S

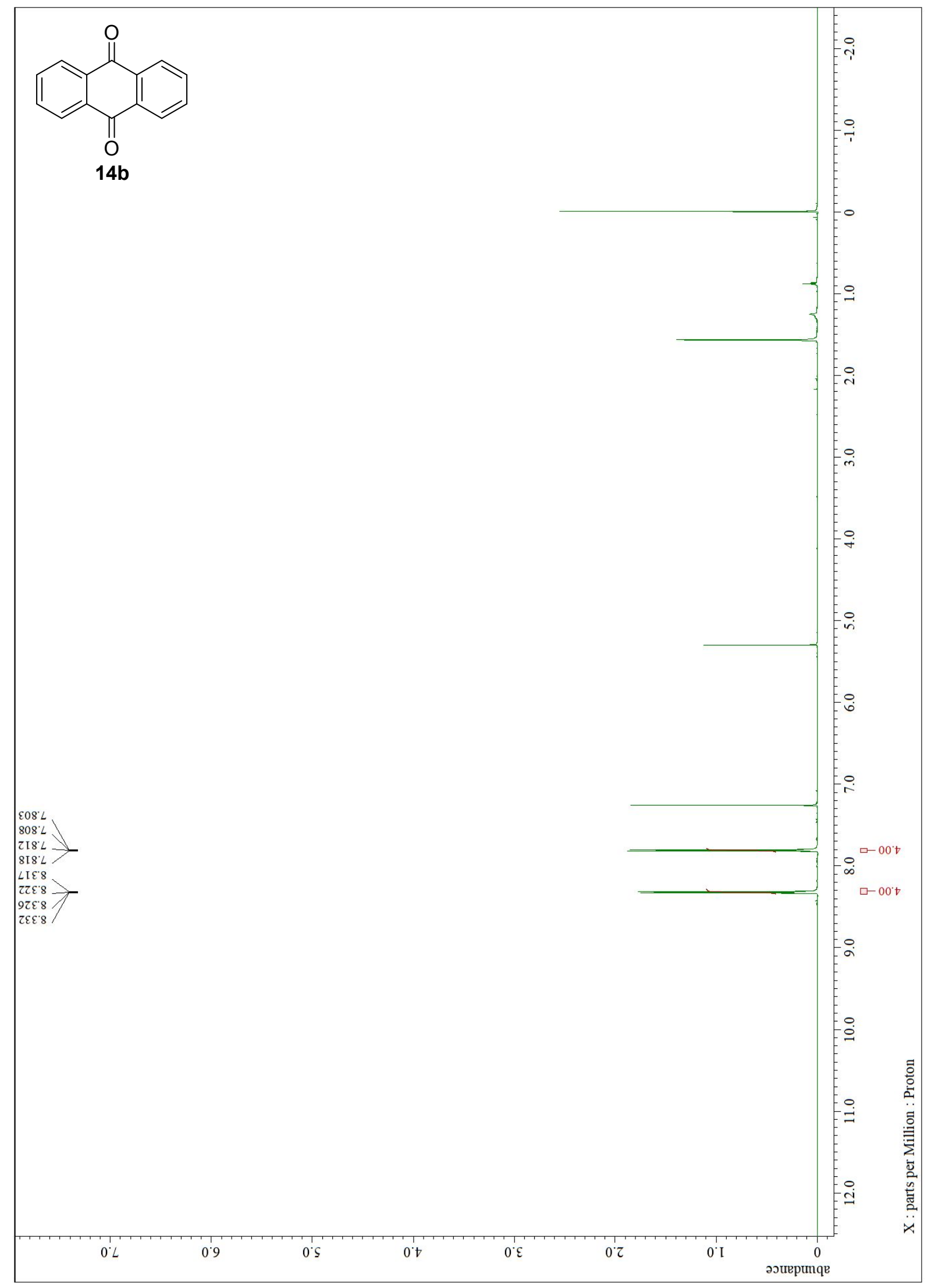


Figure 28S

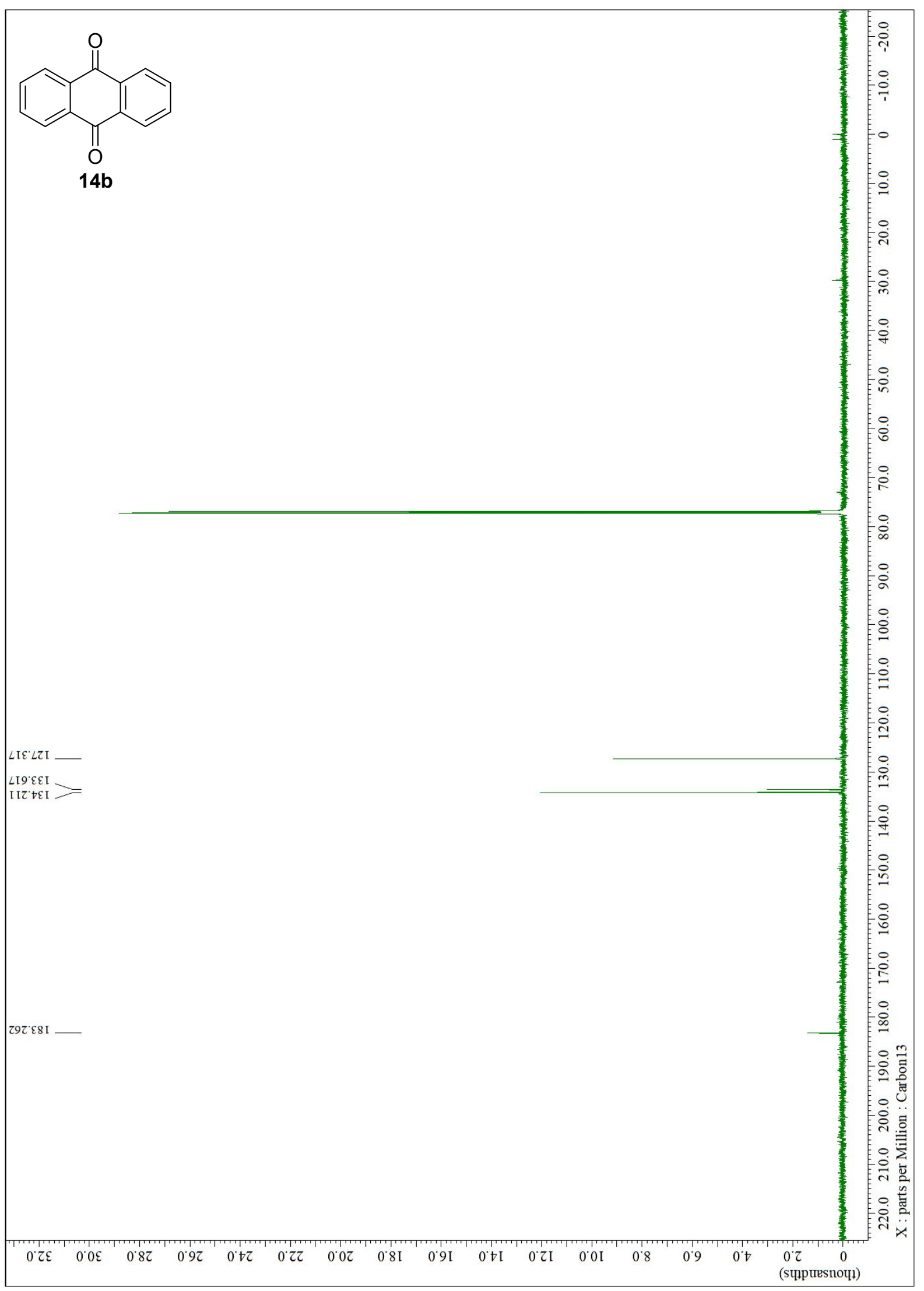

